This item was submitted to Loughborough's Research Repository by the author.

Items in Figshare are protected by copyright, with all rights reserved, unless otherwise indicated.

\title{
Optimum technique for generating angular momentum in accelerated backward giant circles prior to a dismount
}

PLEASE CITE THE PUBLISHED VERSION

PUBLISHER

(C) Human Kinetics

VERSION

AM (Accepted Manuscript)

LICENCE

CC BY-NC-ND 4.0

\section{REPOSITORY RECORD}

Hiley, Michael J., and Maurice R. Yeadon. 2019. "Optimum Technique for Generating Angular Momentum in Accelerated Backward Giant Circles Prior to a Dismount". figshare. https://hdl.handle.net/2134/6012. 
This item was submitted to Loughborough's Institutional Repository (https://dspace.lboro.ac.uk/) by the author and is made available under the following Creative Commons Licence conditions.

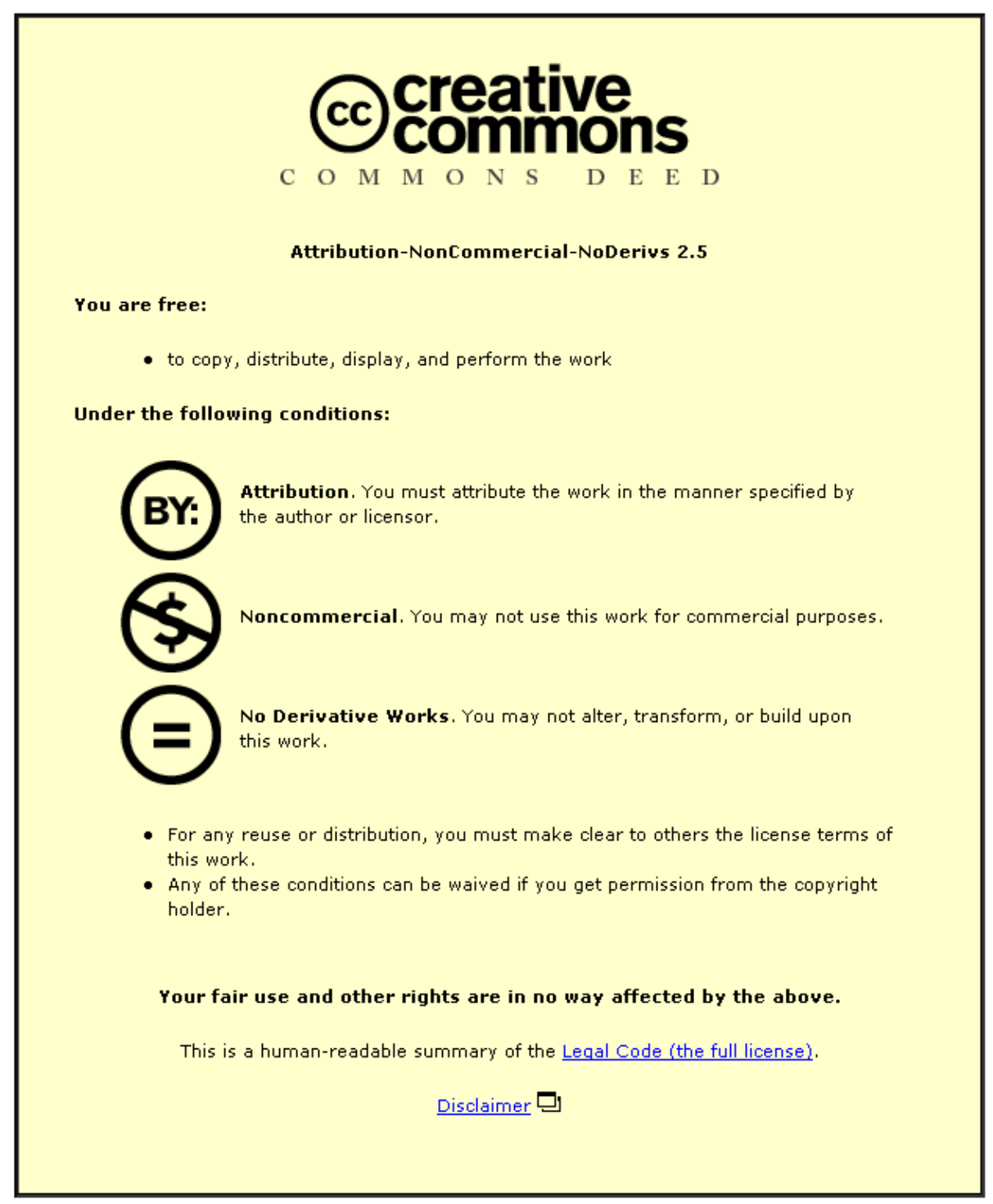

For the full text of this licence, please go to: http://creativecommons.org/licenses/by-nc-nd/2.5/ 


\title{
Optimum technique for generating angular momentum in accelerated backward giant circles prior to a dismount
}

\author{
M.J. Hiley and M.R. Yeadon \\ School of Sport and Exercise Sciences, Loughborough University, Loughborough, Leics, U.K.
}

\begin{abstract}
In Men's Artistic Gymnastics the backward giant circle on high bar is used to produce the angular momentum that the gymnast needs to perform somersaulting dismounts. Dismounts where the gymnast performs two somersaults in the layout (straight body) position require the greatest angular momentum. However, there appear to be two distinct techniques used by elite gymnasts when performing backward giant circles prior to a double layout somersault dismount. The "traditional" technique has been superseded by the "scooped" technique which is now used by the majority of elite gymnasts. To determine whether the scooped technique was better at producing angular momentum a simulation model was used to optimise the angular momentum about the mass centre at release. The model was evaluated using data obtained from a force - video analysis of accelerated giant circles. The model was able to estimate the reaction forces measured by strain gauges on the bar to within $9 \%$ of the peak forces and the body rotation angle to within $1 \%$ of the total rotation. During the optimisations the joint angle time histories of the model were manipulated in order maximise the angular momentum about the model's mass centre at release. Two optima were found which were characteristic of the two backward giant circle techniques used by elite gymnasts. The traditional technique produced more angular momentum than the scooped technique although both techniques were capable of producing sufficient angular momentum for a double layout somersault dismount. As a consequence the preference of elite gymnasts for the scooped technique must be based on factors other than the production of angular momentum.
\end{abstract}

Keywords : gymnastics, high bar, simulation, angular momentum, optimisation

\section{Introduction}

A high bar routine in Men's Artistic Gymnastics consists of a number of circling skills, release and regrasp skills, and a dismount. The backward giant circle is used to link the circling skills and to provide the necessary angular momentum for the release and dismount skills. The basic technique of the backward giant circle comprises hip flexion and shoulder extension (the "closing" phase) as the gymnast passes through the lower part of the circle and hip extension with shoulder flexion (the "opening” phase) as the gymnast passes through the upper part. Those backward giant circles which are used to link the circling skills are often called "regular" giant circles, where the aim is merely to swing from handstand to handstand position using as little flexion and extension as possible (Cheetham, 1984). The giant circles where the gymnast aims to increase his angular velocity, typically before a dismount, are called "accelerated" giant circles.

From observations of elite gymnasts, however, there appear to be two different techniques used in the accelerated giant circles performed before the release for a double layout (straight body) somersault dismount. In the first technique, referred to here as the "traditional" technique, the closing phase occurs during the lower part of the circle and the opening phase occurs near the highest point of the circle (Figure 1). In the second technique, referred to here as the "scooped" technique, the closing phase occurs later than in the traditional technique and the opening phase does not occur until well after the highest point of the circle (Figure 1). 


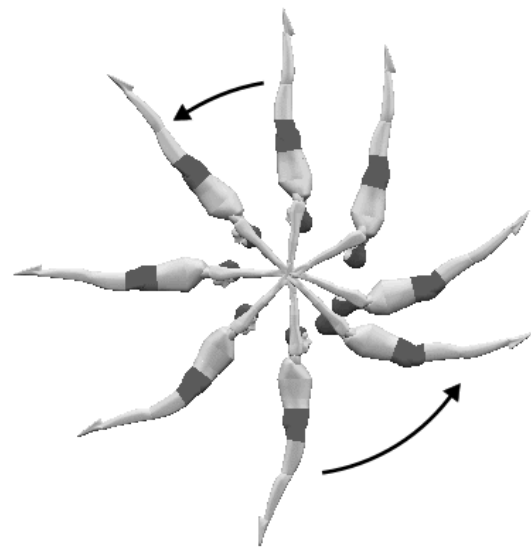

traditional

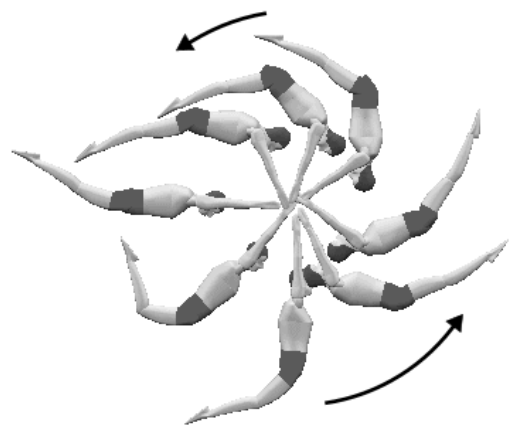

scooped

Figure 1. The "traditional" and "scooped" accelerated backward giant circle techniques which are currently used by elite gymnasts in the "wind-up” prior to double layout somersault dismounts.

Of all the dismounts performed by elite gymnasts it is those that comprise two somersaults in the layout position which require the most angular momentum (Kerwin et al., 1990; Brüggemann et al., 1994). Both techniques appear to be capable of producing sufficient rotation to perform the double layout somersault dismount (Arampatzis and Brüggemann, 1999). It is hypothesised that the scooped technique is better at generating angular momentum than the traditional technique. If this is so it could explain why the scooped technique is preferred by elite gymnasts.

The purpose of this study was to determine optimum technique for generating angular momentum during accelerated giant circles in order to address the above hypothesis. In order to do this a secondary aim was to develop a computer simulation model which could reproduce a recorded performance with good accuracy.

\section{Methods}

A combination of experimental and theoretical approaches was used. Force and video data were collected on an elite gymnast performing accelerated backward giant circles. A computer simulation model was personalised for this gymnast and was used to optimise performance in the backward giant circle leading up to a dismount.

The participant, a member of the Great Britain Men's Senior Artistic Gymnastics Squad, gave informed consent to perform a number of accelerated giant circles as if he were "winding" up for a dismount. The performances were recorded using two genlocked video cameras, a Sony Hi8 Hyper HAD (EVW-300P) and a Sony Digital Handycam (DCR-VX1000E), operating at $50 \mathrm{~Hz}$ with shutter speeds of 1/500 s and $1 / 600 \mathrm{~s}$ respectively. The two cameras were placed $8.5 \mathrm{~m}$ from the high bar with their axes approximately perpendicular. A photocell was attached to the furthest upright of the high bar from the camera with a reflective disc placed on the nearest upright. The photocell was at such a height that the subject's hips broke the beam each time he passed through the lowest point of the giant circle. The breaking of the photocell beam was used to trigger an LED array in view of both video cameras. This event was used to identify synchronous fields in the recordings from the two video cameras.

Prior to the gymnast performing the giant circles a calibration structure comprising 28 spheres of diameter $0.08 \mathrm{~m}$ spanning a volume measuring $1 \mathrm{~m} \times 5 \mathrm{~m} \times 5 \mathrm{~m}$ was positioned with its centre at the midpoint of the high bar so that it included the 
volume traced out by the gymnast during a giant circle. The calibration structure was video recorded by both cameras.

In addition the high bar was instrumented with strain gauges. These were arranged in two full Wheatstone bridge arrangements at each end of the bar and were used to record the horizontal and vertical strain during the backward giant circles. Before the gymnast performed the regular and accelerated giant circles the strain gauges were calibrated by loading the bar with known forces in the horizontal and vertical directions. The bar was loaded to $2.5 \mathrm{kN}$ and $3.0 \mathrm{kN}$ in the horizontal and vertical directions, respectively. The output from the strain gauges was passed through a four channel amplifier (Model 2100, Measurement Group UK) and then through an analogue to digital converter (CED 1401) where it was sampled at $200 \mathrm{~Hz}$ and recorded on a computer (Acorn RISC PC).

The photocell used to synchronise the video data was also used to trigger the collection of the strain data. A delayed trigger was used so that data were collected starting $0.5 \mathrm{~s}$ before the photocell beam was broken, allowing data from the first downswing to be recorded. A total $7.5 \mathrm{~s}$ of data were recorded for each trial. This allowed the gymnast to perform two complete giant circles and a three-quarter circle leading up to release.

The centres of the calibration spheres were digitised in five video fields from both camera views. In each of the movement fields the wrist, elbow, shoulder, hip, knee and ankle joint centres and toes on each side of the body were digitised along with the centre of the subject's head and the centre of the high bar between the subject's hands. Joint centres were assumed to lie on the midlines of adjacent segments when digitising. The data obtained from digitising the images of the calibration spheres and the known locations of the calibration spheres were used to calculate the 11 Direct Linear Transformation parameters for each camera (Abdel-Aziz and Karara, 1971). The synchronised digitised coordinate data from each camera view along with the camera parameters were used to reconstruct the three-dimensional locations of the body landmarks using the Direct Linear Transformation method (Abdel-Aziz and Karara, 1971). Joint angles for the left and right sides were averaged to produce input for a planar simulation model. Quintic splines (Wood and Jennings, 1979) were used to fit the orientation and joint angle time histories so that derivatives could be obtained (Yeadon, 1990a).

The horizontal and vertical loads were each regressed against the strain recordings obtained during the static loading of the high bar. The regression equations were then used to convert all the subsequent strain recordings into forces.

A four segment planar simulation model was developed comprising arm, torso, thigh and lower leg. The high bar and the gymnast's shoulder structure were modelled as damped linear springs (Figure 2). It was assumed that the mass centre of each segment lay on the line joining the segment joint centres. Model parameters comprised the segmental inertia parameters, the stiffness and damping coefficients of the bar and shoulder springs, and parameters defining the maximum torque at each joint. Model input consisted of the initial displacement and velocity of the bar, the initial orientation and angular velocity of the arm, and the joint angle time histories. 


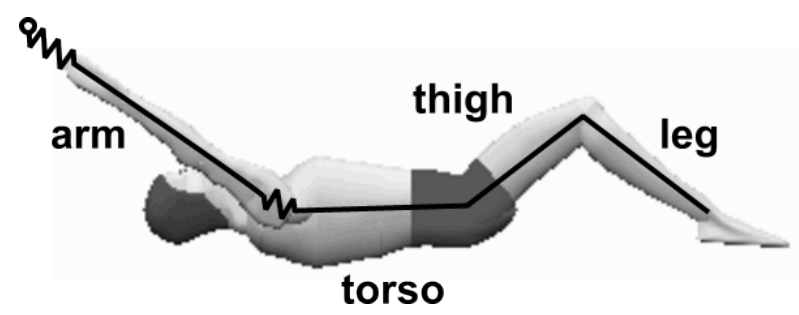

Figure 2. The four segment simulation model with damped springs at the bar and shoulder.

The equations of motion were derived using Newton's Second Law and by taking moments about the neutral bar position and the segment mass centres. The derivation of the equations and their solution is detailed in Appendix A.

Output from the model comprised the time histories of the horizontal and vertical bar displacements, the location and velocity of the mass centre of the model, the rotation angle, the joint torques and the angular momentum of the body about its mass centre. The rotation angle was defined as the angle between the vertical and the line joining the mass centre of the model to the neutral bar position. The angular momentum of the body about its mass centre was calculated using equation (1).

$$
\mathrm{h}=\sum_{\mathrm{i}=1}^{4}\left(\mathrm{I}_{\mathrm{i}} \dot{\phi}_{\mathrm{i}}+\mathrm{m}_{\mathrm{i}}\left(\dot{\mathrm{Z}}_{\mathrm{i}} \mathrm{X}_{\mathrm{i}}-\dot{\mathrm{X}}_{\mathrm{i}} \mathrm{Z}_{\mathrm{i}}\right)\right)
$$

where $\mathrm{I}_{\mathrm{i}}=$ moment of inertia of $\mathrm{i}^{\text {th }}$ segment, $\dot{\phi}_{\mathrm{i}}=$ angular velocity of $\mathrm{i}^{\text {th }}$ segment, $\mathrm{m}_{\mathrm{i}}=$ mass of $i^{\text {th }}$ segment, $X_{i}=\left(x_{i}-x_{c m}\right), Z_{i}=\left(z_{i}-z_{c m}\right),\left(x_{i}, z_{i}\right)=$ mass centre of $i^{\text {th }}$ segment, and $\left(\mathrm{x}_{\mathrm{cm}}, \mathrm{z}_{\mathrm{cm}}\right)=$ whole body mass centre.

The inertia parameters for the model were obtained from anthropometric measurements of the subject of the force and video data collection using the inertia model of Yeadon (1990b). The inertia data presented in Table 1 were used in all the simulations performed in the evaluation of the model and the optimisation of the accelerated backward giant circles. Since the model has single segments representing both arms, both thighs and both legs the values given are the combined values for both limbs. The mass centre distance (MCD) for each segment is from the joint centre nearer the bar and the moments of inertia are about the mass centre of each segment. Parameters defining the strength capabilities of the gymnast were determined by collecting isovelocity dynamometer data and fitting a surface which expressed torque as a function of angle and angular velocity (King and Yeadon, 2002).

The stiffness and damping coefficients for the high bar and shoulder springs were obtained from a combination of experimental and theoretical data. Initially linear regressions were obtained for the force recorded at the bar against the linear displacements and velocities of the centre of the bar. A similar analysis was performed for the shoulder spring. These estimates for the spring coefficients were then used as initial values in an optimisation procedure. During a giant circle where the simulation model was driven using the splined joint angle time histories from the video analysis, the spring coefficients, segmental masses and initial angular velocity in the giant circle were manipulated by the Simulated Annealing algorithm (Goffe et al., 1994) so as to minimise the differences between the rotation angle and bar displacement values obtained from video and the corresponding values obtained from simulation. The joint angle time histories were taken from an accelerated giant circle performed before the two accelerated giant circles which were used in the evaluation of the model. 
Table 1. Segmental inertia parameters of the simulation model

\begin{tabular}{ccccc}
\hline Segment & $\begin{array}{c}\text { Mass } \\
(\mathrm{kg})\end{array}$ & $\begin{array}{c}\text { Length } \\
(\mathrm{m})\end{array}$ & $\begin{array}{c}\text { MCD } \\
(\mathrm{m})\end{array}$ & $\begin{array}{c}\text { Moment of inertia } \\
\left(\mathrm{kg} . \mathrm{m}^{2}\right)\end{array}$ \\
\hline Arm & 10.83 & 0.537 & 0.300 & 0.184 \\
Torso & 35.47 & 0.569 & 0.226 & 1.702 \\
Thigh & 13.91 & 0.374 & 0.151 & 0.174 \\
Leg & 7.59 & NA & 0.227 & 0.187 \\
\hline
\end{tabular}

Note: MCD is the distance of the segment mass centre from the joint centre nearer the bar

The simulation model was evaluated using simulations starting from rotation angles of $0^{\circ}$ and $90^{\circ}$ and ending at a rotation angle of $622^{\circ}$. The model was driven by the joint angle time histories obtained from video analysis of two trials of consecutive accelerated giant circles leading up to release. In all, four simulations were performed for the evaluation of the model. Each simulation was generated using the Simulated Annealing algorithm to optimise the initial arm angle and angular velocity in order to minimise the differences between simulated and actual rotation angle and bar displacement. Comparisons were made between the rotation angles and the reaction forces at the bar obtained from simulation and video analysis. The root mean squared (rms) differences between the simulation and video values were calculated.

The simulation model was used to maximise the final angular momentum about its mass centre after performing 13/4 backward giant circles. Angular momentum about the model's mass centre was chosen to be maximised since this measure governs the rotation in a dismount. The simulation model was implemented with the Simulated Annealing algorithm, which was used to manipulate the parameters that defined the joint angle time histories of the hip and shoulder joints.

The simulations performed during the optimisation were started with the model fully extended (straight) in the handstand position (rotation angle of $0^{\circ}$ ). Each simulation was started with the initial angular velocity obtained from the video analysis of the accelerated giant circles (approximately $1.8 \mathrm{rad}_{\mathrm{s}}^{-1}$ ). Each simulation finished once the model had rotated through $630^{\circ}$. The release angle was chosen when the model reached maximum angular momentum whilst producing a time of flight of at least $1.24 \mathrm{~s}$, which was the average time of flight calculated from 11 performances of double layout somersault dismounts at the Sydney 2000 Olympic Games.

There were five phases in each simulation during which the angles were allowed to change. These corresponded to successively opening, closing, opening, opening more and finally closing where opening involved hip extension and shoulder flexion and closing involved hip flexion and shoulder extension. In changing a joint angle $\theta$, from $\theta_{1}$ to $\theta_{2}$ between times $t_{1}$ and $t_{2}$ the time history was given by:

$$
\theta(\mathrm{t})=\theta_{1}+\left(\theta_{2}-\theta_{1}\right) \mathrm{q}(\mathrm{x})
$$

where $\mathrm{x}=\left(\mathrm{t}-\mathrm{t}_{1}\right) /\left(\mathrm{t}_{2}-\mathrm{t}_{1}\right)$ and $\mathrm{q}(\mathrm{x})=\mathrm{x}^{3}\left(6 \mathrm{x}^{2}-15 \mathrm{x}+10\right)$. Note that $\mathrm{q}(\mathrm{x})$ is a quintic function with the properties:

$$
\dot{\mathrm{q}}(0)=\dot{\mathrm{q}}(1)=\ddot{\mathrm{q}}(0)=\ddot{\mathrm{q}}(1)=0
$$

so that angle changes are effected with zero velocity and acceleration at the endpoints. The actions at the hip and shoulder joints were independent of each other and for simplicity the model kept the knee joint fully extended throughout. The model was restricted to performing the actions in the order specified and further restrictions were 
placed on the magnitudes of these actions so that the hip and shoulder joints could not change from the straight configuration by more than $\pm 180^{\circ}$. The optimisation algorithm manipulated the magnitude and the start and end times of the actions at the hip and shoulder joints in order to maximise the angular momentum about the model's mass centre at the end of the simulation.

In order to determine which of the two backward giant circle techniques could produce the greatest angular momentum two optimisations were performed. In the first optimisation the joint angle time histories were restricted so that a traditional backward giant circle would be produced. Similarly in the second optimisation the joint angle time histories were restricted to produce a scooped backward giant circle. In both cases the restrictions on the joint angle time histories were chosen so as to include the ranges of joint angle time histories of three traditional and eight scooped techniques used at the Sydney Olympics.

To avoid joint angle time histories which exceeded the strength capabilities of the gymnast, the surface fits which expressed torque as a function of angle and angular velocity were used to limit the joint torques at the hip and shoulder. Given a joint angle and angular velocity the surface fit was used to estimate the peak joint torque which the gymnast could produce. If a joint torque in a simulation exceeded the value given by the surface fit, the simulation was given a (angular momentum) penalty. To investigate the effect of strength, or effort, on the optimum solutions the two optimisations were repeated with maximum joint torques reduced by $25 \%$.

\section{Results}

In the evaluation of the model the rms differences between the simulated and recorded rotation angles for the four simulations ranged between $1.4^{\circ}$ and $2.6^{\circ}$ with an average of $2.1^{\circ}$. This corresponded to an error of less than $1 \%$ of the angle rotated through during simulations (Figure 3).

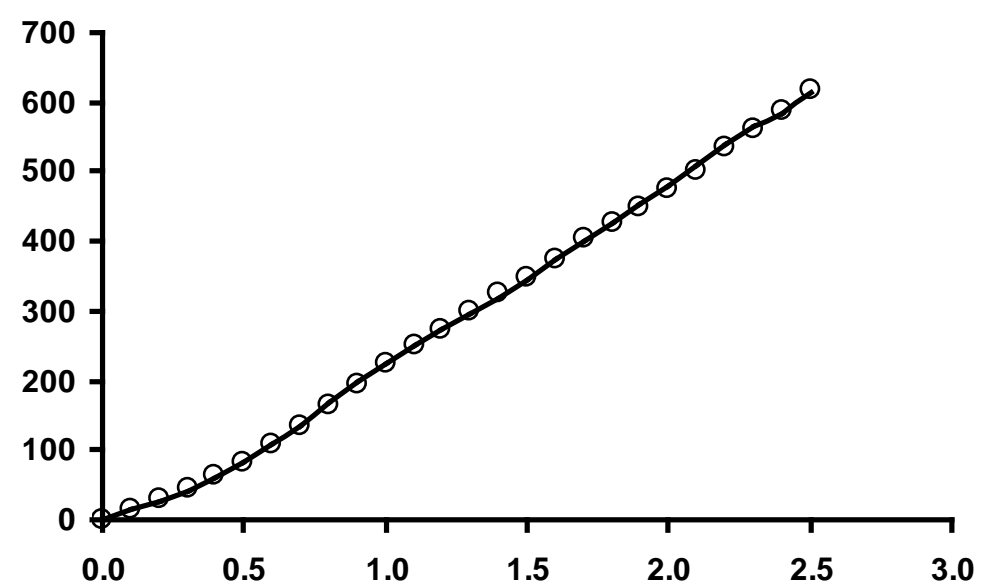

Figure 3. A typical comparison between rotation angles obtained from video analysis (circles) and simulation (solid line).

The model was able to estimate the resultant reaction force measured by the strain gauges to within $9 \%$ of the peak values (Figure 4). For the majority of the time the comparison between the measured and simulated forces was good although the simulation model tended to overestimate the peak reaction forces. 


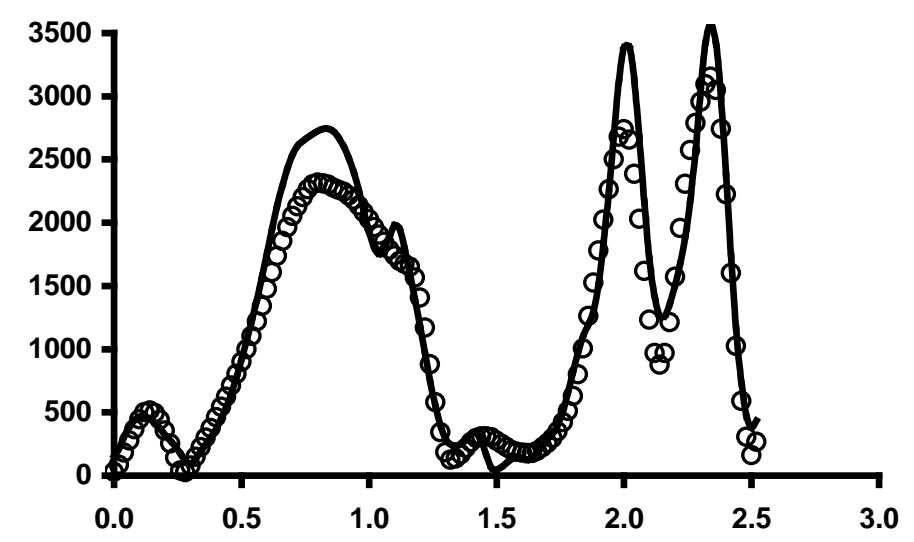

Figure 4. A typical comparison between the resultant bar reaction force obtained from video analysis (circles) and simulation (solid line).

A maximised angular momentum value of $106.2 \mathrm{~kg} \cdot \mathrm{m}^{2} . \mathrm{s}^{-1}$ was obtained from the optimisation of the traditional backward giant circle technique (Figure 5). For the optimisation of the scooped backward giant circle technique an angular momentum value of $95.7 \mathrm{~kg} \cdot \mathrm{m}^{2} . \mathrm{s}^{-1}$ was obtained (Figure 6).

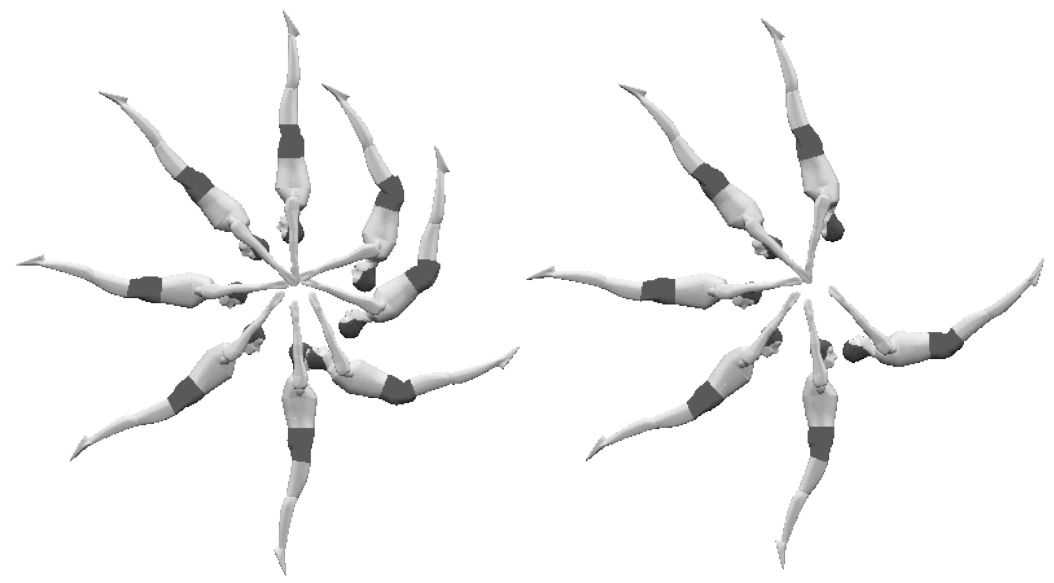

Figure 5. Optimum traditional backward giant circle technique.

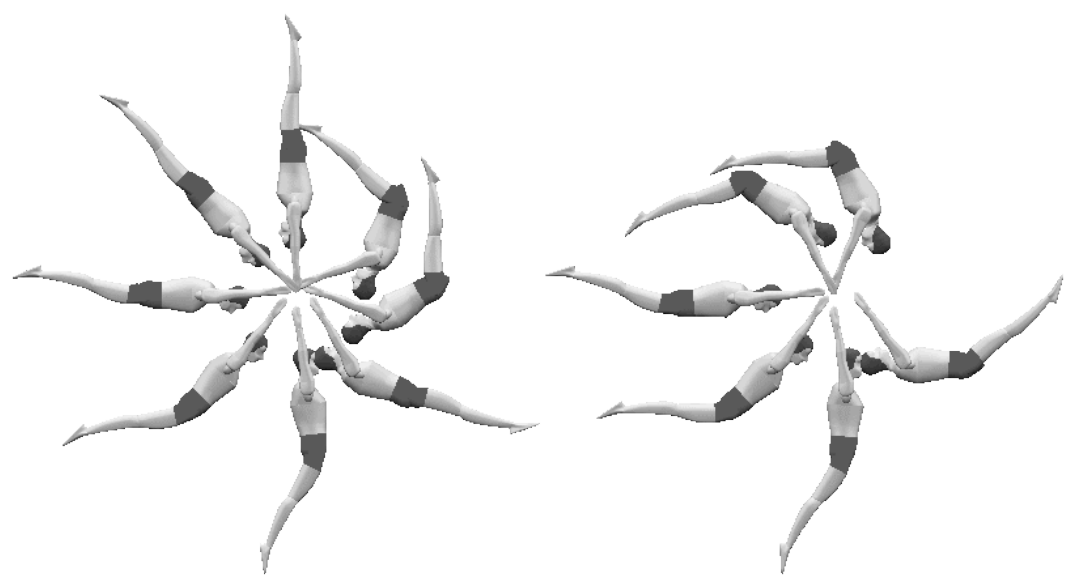

Figure 6. Optimum scooped backward giant circle technique. 
As expected the solutions from the two optimisations with the reduced maximum joint torque produced less angular momentum than the two optimisations where the maximum joint torques were at $100 \%$. The optimum solution when the maximum torque was reduced by $25 \%$ in the traditional backward giant circle technique produced an angular momentum about the model's mass centre of $95.1 \mathrm{~kg} \cdot \mathrm{m}^{2} . \mathrm{s}^{-1}$ at release. The optimised reduced torque scooped backward giant circle produced an angular momentum of $81.6 \mathrm{~kg} \cdot \mathrm{m}^{2} \cdot \mathrm{s}^{-1}$.

\section{Discussion}

The results from the evaluation showed that the simulation model was capable of accurately reproducing a recorded performance in terms of the rotation angle and forces produced at the bar. However, certain limitations are acknowledged with regard to the methods used in the present study. By using a single set of inertia data and muscle strength data the results presented take the form of a single subject study. Although it is likely that different amounts of angular momentum will be produced by varying these two data sets it is unlikely that the results will change appreciably. Both techniques have already been shown to produce similar amounts of angular momentum (Arampatzis and Brüggemann, 1999) and it is to be expected that optimising these techniques would lead to increases in the amounts of angular momentum they produce. A second limitation may be found in the method of changing the angles at the hip and shoulder joints. The joint angle time histories were constrained to five phases of opening and closing. This is sufficient to model the general pattern of movement during the backward giant circles but is unlikely to accurately model smaller changes within this general pattern. It might be expected that using a more sophisticated representation of the joint angle time histories would lead to improvements in the amount of angular momentum produced.

The maximised angular momentum obtained from the optimisation of the traditional technique was sufficient to perform 2.22 straight somersaults (arms by the gymnast's sides) in the subsequent flight phase. Performing a double layout somersault dismount in the straight position requires enough angular momentum to produce 1.75 straight somersaults (or slightly less since the gymnast is short of the vertical on landing). From 11 performances at the Sydney Olympics the average normalised angular momentum was equivalent to 1.63 straight somersaults. The optimised traditional technique therefore produces more angular momentum than is required to perform a double layout somersault dismount. Although the optimised scooped technique produced less angular momentum than the traditional technique the maximised value corresponds to 2.00 straight somersaults, again more than the average of the Olympic performances.

When the maximum joint torque values given by the surface fits were reduced by $25 \%$ the traditional technique still produced more angular momentum (1.99 straight somersaults) than the reduced torque scooped technique (1.71 straight somersaults). However, both techniques produced more angular momentum than the average from the Olympic performances. This suggests that during double layout somersault dismounts gymnasts are working within their strength capabilities.

The aim of the study was to determine the optimum technique for producing angular momentum, with the hypothesis that the scooped technique was better than the traditional technique. The study showed that the traditional technique is capable of producing more angular momentum than the scooped technique, or equivalently, the same angular momentum with less effort. Thus the preference of the scooped technique 
by most elite gymnasts cannot be explained by greater ability in generating angular momentum prior to release. Any advantage of the scooped technique must therefore lie elsewhere.

\section{Acknowledgement}

The authors wish to acknowledge the support of British Gymnastics.

\section{References}

Abdel-Aziz, Y.I., and Karara, H.M. (1971). Direct linear transformation from comparator coordinates into object space coordinates in close-range photogrammetry (ASP Symposium on Close-Range Photogrammetry). pp. 1-18. Falls Church, VA: American Society of Photogrammetry.

Arampatzis, A. and Brüggemann, G-P. (1999). Mechanical energetic processes during the giant swing exercise before dismounts and flight elements on the high bar and the uneven parallel bars. Journal of Biomechanics, 32, 811-820.

Brüggemann, G-P., Cheetham, P.J., Alp, Y. and Arampatzis, D. (1994). Approach to a biomechanical profile of dismounts and release-regrasp skills of the high bar. Journal of Applied Biomechanics, 10, 291-312.

Cheetham, P.J. (1984). Horizontal bar giant swing centre of gravity motion comparisons. In Proceedings of the International Symposium of Biomechanics in Sports (Edited by Terauds, J., Bartheis, K., Mann, R. and Crakes, J.), pp. 99-108. ISBS. Colorado Springs.

Goffe, W.L., Ferrier, G.D. and Rogers, J. (1994). Global optimisation of statistical functions with simulated annealing. Journal of Econometrics, 60, 65-99.

Kerwin, D.G., Yeadon, M.R. and Lee, S.C. (1990). Body configuration in multiple somersault high bar dismounts. International Journal of Sport Biomechanics, 6, 147-156.

King, M.A., and Yeadon, M.R. (2002). Determining subject-specific torque parameters for use in a torque driven simulation model of dynamic jumping. Journal of Applied Biomechanics, 18 (3), 207-217.

Stewart, G.W. (1973). Introduction to matrix computations. London: Academic Press.

Wood, G.A. and Jennings, L.S. (1979). On the use of spline functions for data smoothing. Journal of Biomechanics, 12, 477-479.

Yeadon, M.R. (1990a). The simulation of aerial movement - I. The determination of orientation angles from film data. Journal of Biomechanics, 23, 59-66.

Yeadon, M.R. (1990b). The simulation of aerial movement - II. A mathematical inertia model of the human body. Journal of Biomechanics, 23, 67-74. 


\section{Appendix A}

Equations of motion for simulation model

The equations of motion for the simulation model were derived using Newton's Second Law of Motion and by taking moments about the neutral bar position and the segment mass centres. The system of rigid links and springs was reduced to five equations in five unknowns. The first two equations, (1) and (2), were obtained by resolving the forces horizontally and vertically for the arm segment of the model (Figure 7). Equations (1) and (2) include the forces exerted by the springs at the bar and shoulder with extensions $\mathrm{x}_{\mathrm{b}}, \mathrm{z}_{\mathrm{b}}, \mathrm{x}_{\mathrm{s}}$ and $\mathrm{z}_{\mathrm{s}}$ respectively. The stiffness and damping coefficients of the bar and shoulder springs are denoted by $k_{b x}, k_{b z}, k_{s}, c_{b x}, c_{b z}$ and $c_{s}$.

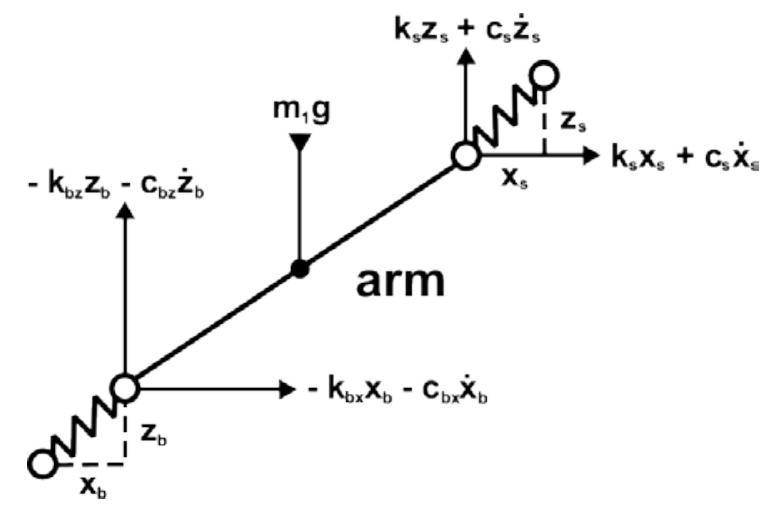

Figure 7. Free body diagram showing the forces acting on the arm segment.

$$
\begin{gathered}
-\mathrm{k}_{\mathrm{bx}} \mathrm{x}_{\mathrm{b}}-\mathrm{c}_{\mathrm{bx}} \dot{\mathrm{x}}_{\mathrm{b}}+\mathrm{k}_{\mathrm{s}} \mathrm{x}_{\mathrm{s}}+\mathrm{c}_{\mathrm{s}} \dot{\mathrm{x}}_{\mathrm{s}}=\mathrm{m}_{1} \ddot{\mathrm{x}}_{1} \\
-\mathrm{k}_{\mathrm{bz}} \mathrm{z}_{\mathrm{b}}-\mathrm{c}_{\mathrm{bz}} \dot{\mathrm{z}}_{\mathrm{b}}+\mathrm{k}_{\mathrm{s}} \mathrm{z}_{\mathrm{s}}+\mathrm{c}_{\mathrm{s}} \dot{\mathrm{z}}_{\mathrm{s}}-\mathrm{m}_{1} \mathrm{~g}=\mathrm{m}_{1} \ddot{\mathrm{z}}_{1}
\end{gathered}
$$

The remaining three equations, (3), (4) and (5), were obtained by resolving forces horizontally and vertically and by taking moments about the neutral bar position $\mathrm{O}$ for the whole model (Figure 8).

$$
\begin{aligned}
& -\mathrm{k}_{\mathrm{bx}} \mathrm{x}_{\mathrm{b}}-\mathrm{c}_{\mathrm{bx}} \dot{\mathrm{x}}_{\mathrm{b}}=\mathrm{m}_{1} \ddot{\mathrm{x}}_{1}+\mathrm{m}_{2} \ddot{\mathrm{x}}_{2}+\mathrm{m}_{3} \ddot{\mathrm{x}}_{3}+\mathrm{m}_{4} \ddot{\mathrm{x}}_{4} \\
& -\mathrm{k}_{\mathrm{bz}} \mathrm{z}_{\mathrm{b}}-\mathrm{c}_{\mathrm{bz}} \dot{\mathrm{z}}_{\mathrm{b}}-\mathrm{g}\left(\mathrm{m}_{1}+\mathrm{m}_{2}+\mathrm{m}_{3}+\mathrm{m}_{4}\right)=\mathrm{m}_{1} \ddot{\mathrm{z}}_{1}+\mathrm{m}_{2} \ddot{\mathrm{z}}_{2}+\mathrm{m}_{3} \ddot{\mathrm{z}}_{3}+\mathrm{m}_{4} \ddot{\mathrm{z}}_{4} \\
& \text { torque = rate of change of angular momentum } \\
& \text { torque = - g( } \left.\mathrm{m}_{1} \mathrm{x}_{1}+\mathrm{m}_{2} \mathrm{x}_{2}+\mathrm{m}_{3} \mathrm{x}_{3}+\mathrm{m}_{4} \mathrm{x}_{4}\right)+\left(-\mathrm{k}_{\mathrm{bz}} \mathrm{z}_{\mathrm{b}}-\mathrm{c}_{\mathrm{bz}} \dot{\mathrm{z}}_{\mathrm{b}}\right) \mathrm{x}_{\mathrm{b}}-\left(-\mathrm{k}_{\mathrm{bx}} \mathrm{x}_{\mathrm{b}}-\mathrm{c}_{\mathrm{bx}} \dot{\mathrm{x}}_{\mathrm{b}}\right) \mathrm{z}_{\mathrm{b}} \\
& \text { rate of change of angular momentum }= \\
& +\mathrm{I}_{1} \ddot{\phi}_{1}+\mathrm{m}_{1} \ddot{\mathrm{z}}_{1} \mathrm{x}_{1}-\mathrm{m}_{1} \ddot{\mathrm{x}}_{1} \mathrm{z}_{1} \\
& +\mathrm{I}_{2} \ddot{\phi}_{2}+\mathrm{m}_{2} \ddot{\mathrm{z}}_{2} \mathrm{x}_{2}-\mathrm{m}_{2} \ddot{\mathrm{x}}_{2} \mathrm{z}_{2} \\
& +\mathrm{I}_{3} \ddot{\phi}_{3}+\mathrm{m}_{3} \ddot{\mathrm{z}}_{3} \mathrm{x}_{3}-\mathrm{m}_{3} \ddot{\mathrm{x}}_{3} \mathrm{z}_{3} \\
& +\mathrm{I}_{4} \ddot{\phi}_{4}+\mathrm{m}_{4} \ddot{\mathrm{z}}_{4} \mathrm{x}_{4}-\mathrm{m}_{4} \ddot{\mathrm{x}}_{4} \mathrm{z}_{4}
\end{aligned}
$$

where $\mathrm{I}_{\mathrm{i}}$ is the moment of inertia of the $\mathrm{i}^{\text {th }}$ segment about its mass centre. 


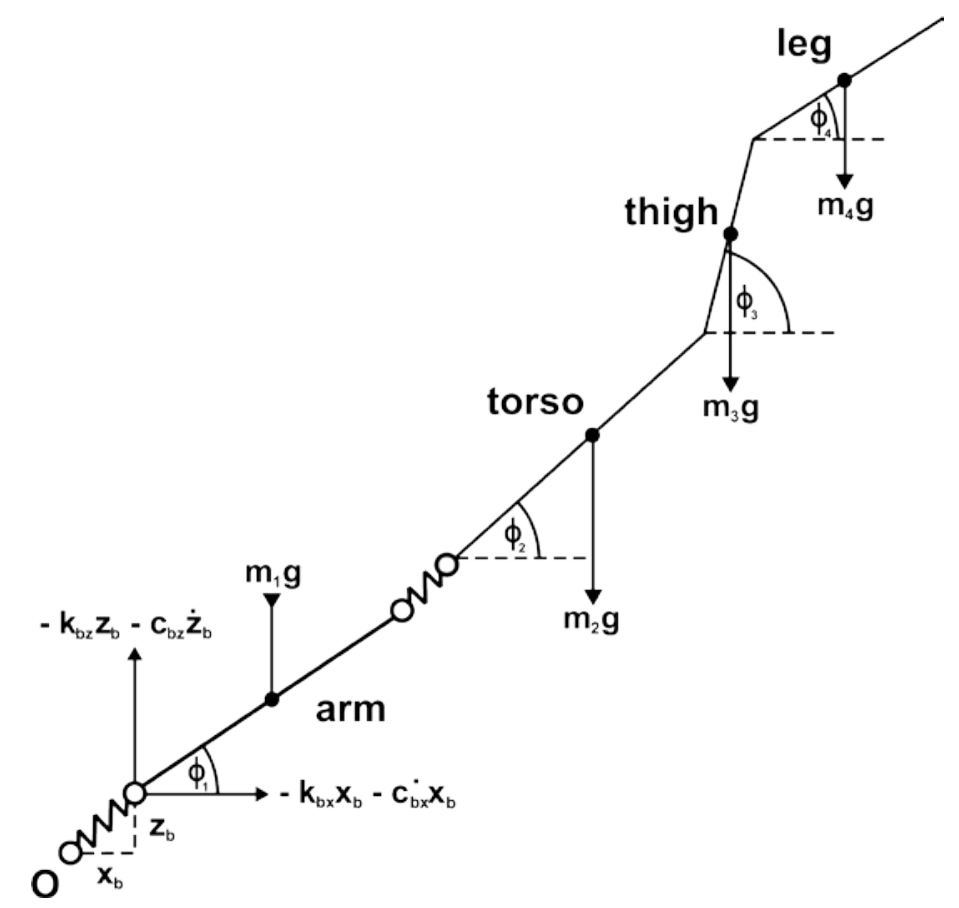

Figure 8. Free body diagram showing the forces acting on the whole body comprising segments 1 (arm), 2 (torso), 3 (thigh) and 4 (leg).

The linear accelerations $\ddot{x}_{i}$ and $\ddot{z}_{i}(i=1,4)$, of the four segment mass centres, may be expressed in terms of $\ddot{\mathrm{x}}_{\mathrm{b}}, \ddot{\mathrm{z}}_{\mathrm{b}}, \ddot{\mathrm{x}}_{\mathrm{s}}, \ddot{\mathrm{z}}_{\mathrm{s}}, \dot{\phi}_{\mathrm{i}}$ and $\ddot{\phi}_{\mathrm{i}}$. The angular velocities and accelerations at the hip, shoulder and knee joints $\left(\dot{\phi}_{\mathrm{i}}\right.$ and $\left.\ddot{\phi}_{\mathrm{i}}, \mathrm{i}=2,4\right)$ were specified as simulation input (from the joint angle time histories) leading to five equations in five unknowns. The unknowns were the linear accelerations of the springs and the angular acceleration of the arm segment $\left(\ddot{\mathrm{x}}_{\mathrm{b}}, \ddot{\mathrm{z}}_{\mathrm{b}}, \ddot{\mathrm{x}}_{\mathrm{s}}, \ddot{\mathrm{z}}_{\mathrm{s}}\right.$ and $\left.\ddot{\phi}_{1}\right)$. The five linear equations were solved numerically for the five unknowns (Stewart, 1973). A second order Runge-Kutta method was used to advance the solution $\left(\mathrm{x}_{\mathrm{b}}, \mathrm{z}_{\mathrm{b}}, \mathrm{x}_{\mathrm{s}}, \mathrm{z}_{\mathrm{s}}\right.$ and $\left.\phi_{1}\right)$ for a time step of 0.0001 s calculating also $\dot{\mathrm{x}}_{\mathrm{b}}, \dot{\mathrm{z}}_{\mathrm{b}}, \dot{\mathrm{x}}_{\mathrm{s}}, \dot{\mathrm{z}}_{\mathrm{s}}$ and $\dot{\phi}_{1}$ as part of the numerical integration. 